ORIGINAL ARTICLE

\title{
A cohort study of mortality among Ontario pipe trades workers
}

\author{
M M Finkelstein, D K Verma
}

Occup Environ Med 2004;61:736-742. doi: 10.1136/oem.2003.011916

See end of article for authors' affiliations .....................

Correspondence to: Dr M Finkelstein, Program in Occupational Health and Environmental Medicine, McMaster University, 1200 Main Street West, Hamilton, Ontario, Canada L8N 3Z5; murray.finkelstein@ utoronto.ca

Accepted 25 February 2004
Aims: To study mortality in a cohort of members of the United Association of Journeymen and Apprentices of the Plumbing and Pipe Fitting Industry of the United States and Canada and to compare results with two previous proportional mortality studies.

Methods: A cohort of 25285 workers who entered the trade after 1949 was assembled from records of the international head office. Mortality was ascertained by linkage to the Canadian Mortality Registry at Statistics Canada. Standardised mortality ratios were computed using Ontario general population mortality rates as the reference.

Results: There were significant increases in lung cancer mortality rates (SMR 1.27; 95\% Cl 1.13 to 1.42). Increased lung cancer risk was observed among plumbers, pipefitters, and sprinkler fitters. Increased risk was observed among workers joining the Union as late as the 1970s. A random effects meta-analysis of this study and the two PMR studies found significant increases in oesophageal (RR 1.24;95\% Cl 1.00 to 1.53), lung (RR 1.31; $95 \% \mathrm{Cl} 1.19$ to 1.44 ), and haematological/lymphatic (RR $1.21 ; 95 \% \mathrm{Cl} 1.08$ to 1.35) malignancies.

Conclusions: The mortality pattern is consistent with the effects of occupational exposure to asbestos. Increased risk due to other respiratory carcinogens such as welding fume cannot be excluded. There are substantial amounts of asbestos in place in industrial and commercial environments. The education and training of workers to protect themselves against inhalation hazards will be necessary well into the future.
$\mathrm{T}$ he United Association of Journeymen and Apprentices of the Plumbing and Pipe Fitting Industry of the United States and Canada (UA) is a multi-craft union whose members are engaged in the fabrication, installation, and servicing of piping systems. There are approximately 326000 United Association members who belong to 321 individual local unions across North America. The work of UA members (plumbers, pipefitters, sprinkler fitters, refrigeration fitters, and service technicians) includes installation of piping and equipment in residential, commercial, and industrial construction sites. Plumbers and pipefitters may encounter many hazardous materials including asbestos, metal fumes, and gases from welding, brazing, and soldering, and solvents used to join plastic pipe. They may also be exposed to hazardous materials from the activities of other tradecraftspersons.

There are two published studies of the mortality experience of members of this union. The first mortality analysis of UA members was published by the National Institute of Occupational Safety and Health (NIOSH) in 1980. ${ }^{1}$ This was a proportional mortality analysis of 3369 deaths in 1971 among white American members of the Union. This study was followed in 1986 by an investigation of proportional mortality among 7121 members or retirees of California locals who died in 1960-79. ${ }^{2}$ Both studies found an increased risk of lung cancer among union members.

With funding from the Ontario Workplace Safety and Insurance Board, a cohort of unionised construction workers was assembled in Ontario for the purpose of studying occupationally associated mortality. We report here a cohort analysis of mortality among 25000 Ontario members of the UA. Follow up was to the end of 1999, so that we are able to report on the more recent experience of members of this union.

\section{METHODS}

\section{Study cohort and mortality follow up}

In September 2000, construction trade unions in Ontario were invited to participate in a retrospective cohort study of mortality among their members. Unions were asked to provide a computer file identifying current and former (separated, retired, deceased) members. Data for members of the Ontario locals of the UA were stored in computer files at the international headquarters in Washington. The UA maintains, for most members, a record with name, date of birth, dates of union initiation and separation, local affiliation(s) with dates of changes, and principal trade within the industry. This record system was automated in 1967-68. In June 2001 we received a file containing information about Ontario members of the Union. Invalid Social Insurance Numbers were recorded for 1829 individuals and they were excluded. An additional 2466 individuals, who had been expelled for non-payment of dues, were also excluded because a coding problem had their termination date earlier than their start date. This left 27024 subjects, all male, for mortality ascertainment.

The cohort roll was linked to the Canadian Mortality Registry (1950-99) at Statistics Canada using probabilistic matching methodology. ${ }^{3}$ Name and birth date were used as primary identifiers. The Social Insurance Number was used internally by Statistics Canada to link to the Canadian Tax Files. This provided the last year in which a tax return was filed and thus additional information about vital status. Because the mortality registry was complete only from 1950, the analysis is limited to the 25285 subjects who entered the trade after 1949.

\section{Trade codes}

The Union assigned a trade code to each subject. These were grouped among: (1) pipefitters $(\mathrm{n}=4211)$; (2) refrigeration fitters $(\mathrm{n}=3149)$; (3) plumbers $(\mathrm{n}=10877)$; and (4) sprinkler fitters $(n=7048)$.

\section{Statistical analysis}

Standardised mortality ratios (SMR) were calculated. Subjects entered follow up at the date of joining the Union. 
Main messages

- Workers in the pipe trades continue to be at increased risk of asbestos associated cancers.

- There are substantial amounts of asbestos in place in industrial and commercial environments.

Follow up was terminated at age 85 , so that any deaths and years at risk after this age were not considered. Ontario male population mortality rates, grouped in five year age and calendar period categories, were used as the reference rates. Confidence intervals were computed assuming that the distribution of observed deaths was distributed according to a Poisson distribution. Calculations were performed with the MANYEARS computer program. ${ }^{4}$

\section{RESULTS}

\section{The study population}

The median age at start of membership was 27 years, with the interquartile range ( 25 th to 75 th centile) being 22 to 35 years. The median start year was 1974 and the interquartile range was 1966 to 1987.

\section{Mortality among Ontario UA members}

Table 1 presents the standardised mortality ratios for malignant and non-malignant deaths among the trade groups. The table is stratified in relation to time from start of membership since occupational cancers generally take 1015 years or more from first exposure to express themselves.

Table 1 shows that observed mortality was generally less than the population average earlier than 20 years from joining the UA. This is a manifestation of the so-called "healthy worker effect". However, one death from mesothelioma and one from asbestosis occurred prior to 20 years, and there was a small excess of lung cancer.

Mortality rates were higher, and closer to the population average, 20-29 years from joining. Mortality rates from "all cancers" were higher than expected, but not statistically significant. There were three deaths attributable to mesothelioma and lung cancer mortality rates were increased. For the pipefitters, the lung cancer SMR was 1.18 (95\% CI 0.85 to $1.60)$, for the plumbers, the SMR was 1.32 (95\% CI 1.01 to 1.69), and for the sprinkler fitters the SMR was 1.53 (95\% CI 1.12 to 2.05). Mortality rates from heart disease and stroke continued to be less than expected.

In the period 30 or more years since joining, cancer mortality rates were higher than the population average, largely attributable to increased lung cancer mortality rates which were increased in all the trade groups.

\section{Cancer mortality}

Table 2 shows cancer mortality in the period 20 years or more after the start of membership, by individual trade and for all trades combined. In the gastrointestinal system, there were increases in oesophageal and colorectal cancer mortality, neither of which was statistically significant, while there was a decreased risk of stomach and pancreatic cancer mortality. In the respiratory tract, there was an excess of laryngeal cancer mortality, and a significant excess of lung cancer. Cancers of the genitourinary system were close to expectation. Deaths from leukaemia were close to expectation, but there was a non-significant increase in mortality from lymphoma.

Table 3 examines lung cancer, and respiratory and circulatory disease mortality rates, 10 or more years after entry, in relation to period of death. Apart from the earliest

\section{Policy implications}

- The education and training of workers to protect themselves against inhalation hazards will be necessary well into the future.

- Smoking is more common among pipe trades workers than among the general population. Smoking cessation programmes should be considered to assist with lowering smoking rates.

period, mortality rates were generally stable during the follow up interval.

\section{Mortality by time period of start of membership}

New asbestos installation generally ceased in the early 1970s and workers entering the trade after that time would not usually be exposed to asbestos installation activities. There is, of course, ongoing exposure to asbestos-in-place. Table 4 shows lung cancer mortality rates during follow up in relation to the time of joining the Union. Among the pipefitters, there is, as yet, no indication of increased mortality risk among members who joined after 1969. It should be noted, however, that the numbers of subjects is relatively small, and that the high risk period after 30 years has not yet been reached. Among the plumbers and sprinkler fitters, however, increased lung cancer risk is apparent among members who joined during the 1970s.

\section{DISCUSSION}

The United Association of Journeymen and Apprentices of the Plumbing and Pipe Fitting Industry of the United States and Canada (UA) is a multi-craft union whose members are engaged in the fabrication, installation, and servicing of piping systems. We report here the first cohort mortality study of members of this Union. Similarly to the American proportional mortality studies performed in previous decades, we found increased risk at a number of cancer sites. It is probable that these increased mortality rates have an occupational causation.

Pipefitters lay out, fabricate and repair piping systems which carry substances used in heating, cooling, lubricating and other processes. Pipefitters perform various activities such as measuring, cutting, welding, brazing, cementing, soldering, and threading joints to join pipes and fabricate sections of piping system. Plumbers plan, install, service, and repair plumbing fixtures, piping equipment, and controls. Generally plumbers work with water pipes. Typical tasks include determining the layout for the plumbing and other materials; cutting holes through walls and floors to accommodate pipes; measuring, cutting, threading, bending, clamping, solvent cementing, or soldering pipe; joining pipe sections and securing them in position; and testing for leaks. Refrigeration and air conditioning mechanics install, maintain, repair, and overhaul commercial and residential refrigeration and air conditioning systems. They measure and cut piping and connect piping using welding and brazing equipment and also recharge systems with refrigerant gases. Besides installation, they may also connect electrical wiring and controls. After an air conditioning system or refrigerator has been installed, mechanics often perform routine maintenance and repair work. Sprinkler fitters fabricate, install, test, maintain, inspect, and repair sprinkler systems. These include wet and dry pipe sprinkler systems, carbon dioxide, chemical, and foam extinguishing systems, stand pipe and hose systems, and fire pump systems. Fire sprinkler fitters perform various activities such as measuring, cutting, 
Table 1 Mortality among Ontario members of the Plumbers and Pipefitters United Association by trade and time from start of membership

\begin{tabular}{|c|c|c|c|c|c|c|c|}
\hline \multirow[b]{3}{*}{ Cause of death } & \multirow[b]{3}{*}{ Trade } & \multicolumn{6}{|c|}{ Years from start of membership } \\
\hline & & \multicolumn{2}{|c|}{$10-19$} & \multicolumn{2}{|c|}{$20-29$} & \multicolumn{2}{|l|}{$\geqslant 30$} \\
\hline & & Obs & $\mathrm{O} / \mathrm{E}$ & Obs & O/E & Obs & O/E \\
\hline \multirow[t]{4}{*}{ All causes } & Pipefitters & 175 & 0.77 & 296 & 0.93 & 346 & 1.02 \\
\hline & Refrigeration & 48 & 0.62 & 73 & 0.87 & 45 & 0.85 \\
\hline & Plumbers & 242 & 0.73 & 401 & 0.89 & 471 & 1.03 \\
\hline & Sprinkler & 166 & 0.78 & 310 & 1.07 & 303 & 1.01 \\
\hline \multirow[t]{4}{*}{ All cancers } & Pipefitters & 50 & 0.82 & 107 & 1.04 & 143 & $1.30^{*}$ \\
\hline & Refrigeration & 13 & 0.61 & 16 & 0.59 & 24 & 1.36 \\
\hline & Plumbers & 78 & 0.93 & 153 & 1.08 & 184 & $1.19^{*}$ \\
\hline & Sprinkler & 45 & 0.86 & 103 & 1.16 & 111 & 1.09 \\
\hline Gastrointestinal cancer; ICD9: 150-158.9 & Pipefitters & 12 & 0.69 & 29 & 1.05 & 25 & 0.90 \\
\hline & Refrigeration & 1 & 0.17 & 5 & 0.7 & 8 & 1.80 \\
\hline & Plumbers & 18 & 0.78 & 30 & 0.8 & 41 & 1.03 \\
\hline & Sprinkler & 9 & 0.62 & 26 & 1.09 & 30 & 1.15 \\
\hline Oesophageal cancer & Pipefitters & 0 & 0 & 4 & 1.2 & 1 & 0.31 \\
\hline & Refrigeration & 0 & 0 & 0 & 0 & 2 & 3.75 \\
\hline & Plumbers & 3 & 1.2 & 7 & 1.5 & 5 & 1.02 \\
\hline & Sprinkler & 1 & 0.66 & 4 & 1.4 & 7 & 2.16 \\
\hline Stomach cancer & Pipefitters & 6 & 1.79 & 2 & 0.43 & 4 & 0.94 \\
\hline & Refrigeration & 0 & 0 & 1 & 0.86 & 1 & 1.50 \\
\hline & Plumbers & 5 & 1.1 & 4 & 0.63 & 4 & 0.66 \\
\hline & Sprinkler & 3 & 1.1 & 3 & 0.74 & 2 & 0.50 \\
\hline Colorectal cancer & Pipefitters & 2 & 0.3 & 15 & 1.3 & 13 & 1.07 \\
\hline & Refrigeration & 0 & 0 & 2 & 0.67 & 2 & 1.04 \\
\hline & Plumbers & 7 & 0.73 & 16 & 1.02 & 21 & 1.24 \\
\hline & Sprinkler & 4 & 0.67 & 12 & 1.22 & 15 & 1.35 \\
\hline Pancreatic cancer & Pipefitters & 4 & 1.2 & 6 & 1.17 & 1 & 0.20 \\
\hline & Refrigeration & 1 & 0.93 & 2 & 1.53 & 2 & 2.50 \\
\hline & Plumbers & 1 & 0.23 & 2 & 0.29 & 4 & 0.56 \\
\hline & Sprinkler & 0 & 0 & 6 & 1.36 & 5 & 1.05 \\
\hline Laryngeal cancer & Pipefitters & 2 & 2.05 & 1 & 0.63 & 1 & 0.70 \\
\hline & Refrigeration & 0 & 0 & 0 & 0 & 0 & 0.00 \\
\hline & Plumbers & 1 & 0.8 & 5 & 2.34 & 3 & 1.40 \\
\hline & Sprinkler & 1 & 1.32 & 2 & 1.49 & 2 & 1.41 \\
\hline Lung cancer & Pipefitters & 23 & 1.12 & 42 & 1.18 & 56 & $1.53^{*}$ \\
\hline & Refrigeration & 7 & 1.02 & 3 & 0.33 & 7 & 1.21 \\
\hline & Plumbers & 28 & 1.04 & 63 & $1.32^{*}$ & 56 & 1.08 \\
\hline & Sprinkler & 18 & 1.1 & 45 & $1.53^{*}$ & 45 & 1.32 \\
\hline Pleural mesothelioma & Pipefitters & 0 & & 2 & & 1 & \\
\hline & Refrigeration & 0 & & 0 & & 0 & \\
\hline & Plumbers & 1 & & 1 & & 2 & \\
\hline & Sprinkler & 0 & & 0 & & 1 & \\
\hline Kidney cancer & Pipefitters & 1 & 0.59 & 2 & 0.77 & 1 & 0.41 \\
\hline & Refrigeration & 0 & 0 & 1 & 1.4 & 0 & 0.00 \\
\hline & Plumbers & 1 & 0.44 & 2 & 0.53 & 5 & 1.34 \\
\hline & Sprinkler & 3 & 2.1 & 4 & 1.7 & 1 & 0.41 \\
\hline Bladder cancer & Pipefitters & 0 & 0 & 3 & 1.2 & 5 & 1.56 \\
\hline & Refrigeration & 2 & 4.6 & 0 & 0 & 1 & 2.01 \\
\hline & Plumbers & 1 & 0.57 & 2 & 0.61 & 7 & 1.70 \\
\hline & Sprinkler & 1 & 0.93 & 2 & 0.98 & 1 & 0.38 \\
\hline Prostate cancer & Pipefitters & 0 & 0 & 4 & 0.57 & 16 & 1.33 \\
\hline & Refrigeration & 1 & 1.06 & 0 & 0 & 3 & 1.62 \\
\hline & Plumbers & 3 & 0.85 & 12 & 1.43 & 14 & 0.98 \\
\hline & Sprinkler & 0 & 0 & 2 & 0.38 & 5 & 0.54 \\
\hline Brain cancer & Pipefitters & 3 & 1.18 & 4 & 1.37 & 4 & 1.85 \\
\hline & Refrigeration & 1 & 1.08 & 1 & 1.24 & 0 & 0 \\
\hline & Plumbers & 4 & 1.03 & 5 & 1.06 & 6 & 1.69 \\
\hline & Sprinkler & 3 & 1.16 & 1 & 0.32 & 3 & 1.27 \\
\hline Blood and lymphatic; ICD9: 200-208 & Pipefitters & 2 & 0.35 & 5 & 0.59 & 13 & 1.40 \\
\hline & Refrigeration & 0 & 0 & 2 & 0.84 & 4 & 2.66 \\
\hline & Plumbers & 6 & 0.68 & 10 & 0.8 & 19 & 1.43 \\
\hline & Sprinkler & 5 & 0.87 & 9 & 1.12 & 10 & 1.15 \\
\hline Leukaemia (myelogenous and & Pipefitters & 1 & 0.59 & 2 & 0.69 & 3 & 0.89 \\
\hline lymphatic); ICD9: 204, 205, 208 & Refrigeration & 0 & 0 & 0 & 0 & 1 & 0.68 \\
\hline & Plumbers & 3 & 1.11 & 3 & 0.69 & 6 & 1.27 \\
\hline & Sprinkler & 2 & 1.14 & 3 & 1.09 & 6 & 1.94 \\
\hline Lymphoma; ICD9: 200-202 & Pipefitters & 1 & 0.38 & 3 & 0.81 & 8 & 2.07 \\
\hline & Refrigeration & 0 & 0 & 1 & 0.94 & 3 & 4.69 \\
\hline & Plumbers & 2 & 0.49 & 4 & 0.71 & 10 & 1.74 \\
\hline & Sprinkler & 3 & 1.11 & 4 & 1.1 & 3 & 0.79 \\
\hline Circulatory disease (heart & Pipefitters & 74 & 0.77 & 116 & 0.86 & 116 & 0.84 \\
\hline disease and stroke) & Refrigeration & 18 & 0.63 & 38 & 1.16 & 15 & 0.71 \\
\hline & Plumbers & 88 & 0.68 & 163 & 0.92 & 173 & 0.97 \\
\hline & Sprinkler & 53 & 0.65 & 114 & 1 & 110 & 0.94 \\
\hline
\end{tabular}


Table 1 Continued

\begin{tabular}{|c|c|c|c|c|c|c|c|}
\hline \multirow[b]{3}{*}{ Cause of death } & \multirow[b]{3}{*}{ Trade } & \multicolumn{6}{|c|}{ Years from start of membership } \\
\hline & & \multicolumn{2}{|c|}{$10-19$} & \multicolumn{2}{|c|}{$20-29$} & \multicolumn{2}{|l|}{$\geqslant 30$} \\
\hline & & Obs & O/E & Obs & O/E & Obs & O/E \\
\hline \multirow[t]{4}{*}{ Respiratory disease } & Pipefitters & 6 & 0.58 & 20 & 1.04 & 36 & 1.27 \\
\hline & Refrigeration & 3 & 0.89 & 2 & 0.39 & 3 & 0.70 \\
\hline & Plumbers & 8 & 0.55 & 23 & 0.93 & 26 & 0.77 \\
\hline & Sprinkler & 7 & 0.78 & 24 & 1.54 & 20 & 0.93 \\
\hline Chronic obstructive pulmonary & Pipefitters & 2 & 0.40 & 7 & 0.66 & 22 & 1.33 \\
\hline \multirow[t]{3}{*}{ disease; ICD9: 490-496 } & Refrigeration & 1 & 0.59 & 2 & 0.71 & 2 & 0.80 \\
\hline & Plumbers & 4 & 0.59 & 15 & 1.12 & 15 & 0.77 \\
\hline & Sprinkler & 2 & 0.48 & 16 & 1.95 & 9 & 0.72 \\
\hline \multirow[t]{4}{*}{ Pneumoconiosis } & Pipefitters & 1 & & 1 & & 1 & \\
\hline & Refrigeration & 0 & & 0 & & 1 & \\
\hline & Plumbers & 0 & & 1 & & 0 & \\
\hline & Sprinkler & 0 & & 1 & & 2 & \\
\hline \multirow{4}{*}{ Violent causes } & Pipefitters & 32 & 1.28 & 19 & 1.12 & 11 & 1.09 \\
\hline & Refrigeration & 10 & 0.97 & 3 & 0.59 & 1 & 0.59 \\
\hline & Plumbers & 32 & 0.63 & 19 & 0.57 & 19 & 1.11 \\
\hline & Sprinkler & 32 & 0.88 & 21 & 0.91 & 15 & 1.32 \\
\hline
\end{tabular}

threading, bending, and soldering. Typical tasks include selecting the type and size of pipe required; installing clamps, brackets, and hangers to support piping system and sprinkler and fire protection equipment, using hand and power tools; selecting, measuring, cutting, reaming, and threading pipe and mount prepared pipe in supports; joining pipes and piping sections using soldering and welding equipment; and connecting piping system to water mains, supply tanks, pumps, compressors, and control equipment.

The potential occupational exposures of pipe trade workers include the following known or suspected carcinogens: acrylonitrile (lung, bowel); arsenic (lung, skin); asbestos (lung, pleural and peritoneal cavity, gastrointestinal tract); benzene (leukaemia); beryllium (lung, bone); cadmium (lung, prostate); chromium (larynx, nasal cavity); nickel (nasal cavity, lung); styrene-butadiene rubber (lymphatic system); tar (scrotum, skin); and vinyl chloride (liver, brain, lung). Exposure to vinyl chloride, acrylonitrile, and styrenebutadiene rubber would be through the use of plastic pipes; however, these came into widespread use only in the 1960s.

The first mortality analysis of UA members was published by NIOSH in $1980 .{ }^{1}$ This was a proportional mortality analysis of 3369 deaths in 1971 among white American members of the Union. The PMR for all malignant neoplasms was significantly increased (PMR 1.13). There were significant increases for cancers of the oesophagus (PMR 1.55) and lung (PMR 1.22). PMRs for heart disease and non-malignant respiratory diseases were close to 1.0. There were no deaths attributed to asbestosis, but there were seven deaths from mesothelioma.

This study was followed by a 1986 study of proportional mortality among 7121 members or retirees of California locals who died in 1960-79. ${ }^{2}$ In that study there were significant increases in the PMRs for stomach (PMR 1.29), lung (PMR 1.41), and brain (PMR 1.50) cancers, and malignancies of the blood and lymphatics (PMR 1.24). There was no excess of respiratory disease (PMR 0.98). Mesothelioma was the underlying cause of death in 16 cases.

Proportional mortality studies are susceptible to an artifactual effect that has been labelled "borrowing". Suppose, for instance, that employees in a given company or industry suffered less heart disease than the general population. This might occur because people able to acquire jobs are healthier than the average of the entire population, which would include the chronically ill. With use of a proportional mortality analysis for all the deaths in the population, one may find an apparent increase in risk for the other causes of death (for example, cancer), even though the death rate of disease from these other causes for the working population is the same as that of the general population. This is because of the reduction in mortality for one cause of death (heart disease), and because we are analysing the proportional distribution of death among the 100 per cent of all deaths, the proportion of deaths from the other causes must inevitably rise. The present study of Ontario members of the UA is a retrospective cohort mortality study. Because we had knowledge of the vital status of all members of the UA cohort, rather than just those who died, it was possible to compute mortality rates directly, rather than simply comparing the pattern of mortality as in a PMR analysis. Mortality rates from circulatory disorders were, in fact, less than expected, although not markedly so. This would lead to some inflation of cancer mortality rates in a PMR study.

In order to compare the results for cancer mortality among the three North American studies of the UA, we have assumed that the PMRs measured in the American studies are approximately equal to SMRs. This will be the case if overall mortality rates are roughly similar to those of the general population. ${ }^{5}$ We have also computed a pooled result, using a random effects meta-analysis model. ${ }^{6}$ In the random effects model it is not presumed that each study is estimating the same risk, as would be the case in a fixed effects model; rather the results of the studies are presumed to be normally distributed around some "global" estimate for members of the trade.

Table 5 shows the results of the comparison. Oesophageal cancer rates were increased in all three studies, and the combined relative risk, 1.24, was statistically significant. Stomach cancer rates were substantially increased only in the California study, and the combined risk was close to 1.0. Colorectal cancer rates were modestly increased in two of three studies, and the combined risk was again close to 1.0. Laryngeal cancer PMR was reported only in the California study. The combined risk was 1.2, close to the combined estimate for oesophageal and lung cancer. Because of the rarity of the outcome, there was inadequate power for the increased laryngeal cancer rate to achieve statistical significance. There was a consistent excess of lung cancer among the three studies, with a combined relative risk of 1.31 (95\% CI 1.19 to 1.44$)$.

Mortality rates from cancers of the haematological and lymphatic systems were increased in all three studies. These 
Table 2 Cancer mortality among Ontario members of the Plumbers and Pipefitters United Association 20 or more years from start of membership

\begin{tabular}{|c|c|c|c|c|}
\hline Cause of death & Trade & Obs & O/E & $95 \% \mathrm{Cl}$ \\
\hline \multirow[t]{5}{*}{ Oesophageal cancer } & Pipefitters & 5 & 0.76 & 0.25 to 1.8 \\
\hline & Refrigeration & 2 & 1.40 & 0.17 to 5.2 \\
\hline & Plumbers & 12 & 1.26 & 0.65 to 2.2 \\
\hline & Sprinkler & 11 & 1.80 & 0.90 to 3.2 \\
\hline & Total & 30 & 1.27 & 0.86 to 1.81 \\
\hline \multirow[t]{5}{*}{ Stomach cancer } & Pipefitters & 6 & 0.67 & 0.24 to 1.5 \\
\hline & Refrigeration & 2 & 1.07 & 0.13 to 3.8 \\
\hline & Plumbers & 8 & 0.65 & 0.28 to 1.3 \\
\hline & Sprinkler & 5 & 0.62 & 0.20 to 1.4 \\
\hline & Total & 21 & 0.67 & 0.41 to 1.02 \\
\hline \multirow[t]{5}{*}{ Colorectal cancer } & Pipefitters & 28 & 1.17 & 0.78 to 1.7 \\
\hline & Refrigeration & 4 & 0.82 & 0.22 to 2.1 \\
\hline & Plumbers & 37 & 1.12 & 0.79 to 1.6 \\
\hline & Sprinkler & 27 & 1.29 & 0.85 to 1.9 \\
\hline & Total & 96 & 1.16 & 0.94 to 1.42 \\
\hline \multirow[t]{5}{*}{ Pancreatic cancer } & Pipefitters & 7 & 0.69 & 0.28 to 1.4 \\
\hline & Refrigeration & 4 & 1.90 & 0.52 to 4.9 \\
\hline & Plumbers & 6 & 0.43 & 0.16 to 0.94 \\
\hline & Sprinkler & 11 & 1.21 & 0.60 to 2.2 \\
\hline & Total & 28 & 0.79 & 0.52 to 1.14 \\
\hline \multirow{5}{*}{ Laryngeal cancer } & Pipefitters & 2 & 0.67 & 0.08 to 2.4 \\
\hline & Refrigeration & 0 & 0.00 & 0 to 6.2 \\
\hline & Plumbers & 8 & 1.86 & 0.80 to 3.7 \\
\hline & Sprinkler & 4 & 1.47 & 0.40 to 3.8 \\
\hline & Total & 14 & 1.32 & 0.72 to 2.21 \\
\hline \multirow[t]{5}{*}{ Lung cancer } & Pipefitters & 98 & 1.36 & 1.1 to 1.7 \\
\hline & Refrigeration & 10 & 0.68 & 0.32 to 1.2 \\
\hline & Plumbers & 119 & 1.19 & 0.99 to 1.4 \\
\hline & Sprinkler & 90 & 1.43 & 1.2 to 1.8 \\
\hline & Total & 317 & 1.27 & 1.13 to 1.42 \\
\hline \multirow[t]{4}{*}{ Pleural mesothelioma } & Pipefitters & 3 & - & \\
\hline & Refrigeration & 0 & - & \\
\hline & Plumbers & 3 & - & \\
\hline & Sprinkler & 1 & - & \\
\hline \multirow[t]{5}{*}{ Kidney cancer } & Pipefitters & 3 & 0.60 & 0.12 to 1.8 \\
\hline & Refrigeration & 1 & 0.91 & 0.02 to 5.1 \\
\hline & Plumbers & 7 & 0.93 & 0.38 to 1.9 \\
\hline & Sprinkler & 5 & 1.02 & 0.33 to 2.4 \\
\hline & Total & 16 & 0.86 & 0.49 to 1.40 \\
\hline \multirow{5}{*}{ Bladder cancer } & Pipefitters & 8 & 1.40 & 0.61 to 2.8 \\
\hline & Refrigeration & 1 & 0.83 & 0.02 to 4.6 \\
\hline & Plumbers & 9 & 1.22 & 0.56 to 2.3 \\
\hline & Sprinkler & 3 & 0.64 & 0.13 to 1.9 \\
\hline & Total & 21 & 1.11 & 0.68 to 1.68 \\
\hline \multirow[t]{5}{*}{ Prostate cancer } & Pipefitters & 20 & 1.05 & 0.64 to 1.6 \\
\hline & Refrigeration & 3 & 0.79 & 0.16 to 2.3 \\
\hline & Plumbers & 26 & 1.14 & 0.74 to 1.7 \\
\hline & Sprinkler & 7 & 0.48 & 0.19 to 0.99 \\
\hline & Total & 56 & 0.93 & 0.70 to 1.21 \\
\hline \multirow[t]{5}{*}{ Brain cancer } & Pipefitters & 8 & 1.57 & 0.68 to 3.1 \\
\hline & Refrigeration & 1 & 1 & 0.02 to 4.6 \\
\hline & Plumbers & 11 & 1.33 & 0.66 to 2.4 \\
\hline & Sprinkler & 4 & 0.73 & 0.20 to 1.9 \\
\hline & Total & 24 & 1.19 & 0.76 to 1.77 \\
\hline Blood and lymphatic; & Pipefitters & 18 & 1.01 & 0.60 to 1.6 \\
\hline \multirow[t]{4}{*}{ ICD9: 200-208 } & Refrigeration & 6 & 1.54 & 0.56 to 3.4 \\
\hline & Plumbers & 29 & 1.16 & 0.78 to 1.7 \\
\hline & Sprinkler & 19 & 1.14 & 0.68 to 1.8 \\
\hline & Total & 72 & 1.14 & 0.89 to 1.44 \\
\hline Leukaemia (myelogenous and & Pipefitters & 5 & 0.79 & 0.26 to 1.9 \\
\hline lymphatic); ICD9: 204, 205, 208 & Refrigeration & 1 & 0.43 & 0.01 to 2.4 \\
\hline & Plumbers & 9 & 0.99 & 0.45 to 1.9 \\
\hline & Sprinkler & 9 & 1.53 & 0.70 to 2.9 \\
\hline & Total & 24 & 1.02 & 0.65 to 1.52 \\
\hline Lymphoma; ICD9:200-202 & Pipefitters & 11 & 1.45 & 0.72 to 2.6 \\
\hline & Refrigeration & 4 & 2.30 & 0.64 to 6.0 \\
\hline & Plumbers & 14 & 1.22 & 0.67 to 2.0 \\
\hline & Sprinkler & 7 & 0.93 & 0.38 to 1.9 \\
\hline & Total & 36 & 1.27 & 0.89 to 1.76 \\
\hline
\end{tabular}

are a heterogeneous group of tumours, comprising leukaemia and lymphomas. In the Ontario study, the increased risk was only for lymphomas, and not leukaemias. A similar pattern was observed in the California study. Because of the reporting in the published papers it was not possible to subclassify the tumours in the comparative analysis. If it is hypothesised that these tumours might be associated with solvent or organic chemical exposures, then one might predict that plumbers, who work with plastic pipe and adhesives, might have higher rates than the pipefitters. The 
Table 3 Lung cancer, respiratory disease and circulatory disease mortality ratios among members of the Plumbers and Pipefitters United Association by year of death

\begin{tabular}{|c|c|c|c|c|c|c|c|c|c|c|c|}
\hline \multirow[b]{3}{*}{ Trade } & \multicolumn{11}{|c|}{ Year of death } \\
\hline & \multicolumn{2}{|c|}{$1960-68$} & \multicolumn{2}{|c|}{$1969-78$} & \multicolumn{2}{|c|}{ 1979-88 } & \multicolumn{2}{|c|}{ 1989-99 } & \multicolumn{3}{|c|}{ Total (1960-99) } \\
\hline & Obs & SMR & Obs & SMR & Obs & SMR & Obs & SMR & Obs & EXP & SMR $(95 \% \mathrm{Cl})$ \\
\hline $\begin{array}{l}\text { Lung cancer } \\
\text { All trades }\end{array}$ & 3 & 0.34 & 63 & 1.27 & 167 & 1.34 & 222 & 1.24 & 455 & 362 & $1.26(1.14$ to 1.38$)$ \\
\hline Respiratory dis & ease & & & & & & & & & & \\
\hline $\begin{array}{l}\text { All trades } \\
\text { Circulatory dise }\end{array}$ & $\begin{array}{c}0 \\
\text { ease }\end{array}$ & 0 & 25 & 0.86 & 64 & 0.96 & 106 & 1.02 & 195 & 207 & $0.94(0.81$ to 1.08$)$ \\
\hline All trades & 9 & 0.1 & 212 & 0.8 & 435 & 0.95 & 558 & 0.94 & 1214 & 1388 & $0.87(0.83$ to 0.93$)$ \\
\hline
\end{tabular}

Only deaths occurring 10 or more years from start of membership are included.

bottom two rows of table 5 show the mortality results among the subgroups of plumbers and pipefitters. Rates were higher among the plumbers in each of the studies. A Poisson regression analysis, combining the three studies, estimated that the relative risk for the plumbers, compared to the pipefitters, was 1.15, but the difference was not significant $(p=0.23)$. The interpretation of these results is not clear. There might be an association between solvents or welding/ soldering and lymphoma, but the medical literature offers no consistent relation between lymphoma and occupation. These may be chance findings.

The mortality pattern among UA members, showing increased mortality rates from oesophageal, laryngeal, and lung cancers, and mesothelioma, is consistent with occupational exposure to asbestos. Although the workers may have been exposed to other lung carcinogens, such as welding fume, it is not possible to separate their effects from that of asbestos exposure.

Smoking is the main cause of lung cancer. Blue collar workers tend to smoke more than others. In a 1987-90 survey in the United States, ${ }^{7} 40 \%$ of plumbers and pipefitters were smokers. During this period, smoking prevalence was $24 \%$ among white collar workers, $39 \%$ among blue collar workers, $35 \%$ among service workers, and 23\% among farm workers. The weighted average among all adults was 30\%. The Appendix gives a calculation of the relative risk of lung cancer attributable to smoking among plumbers and pipefitters if we take the 1987-90 prevalence rates for comparison and assume that cigarette smoking leads to a 10-fold increase in lung cancer risk. We find a relative risk attributable to smoking of about $24 \%$. The lung cancer risk among UA members is modestly higher than this estimate, but both estimates are uncertain.
The occurrence of mesothelioma and asbestosis confirms that occupational exposure to asbestos has played a role in the health of these workers.

There are a number of limitations to our study. Mortality was ascertained by probabilistic record linkage at Statistics Canada. We may have missed some deaths while falsely classifying some living individuals as deceased. This may have an effect on our calculated SMRs, probably in the direction of reducing them if many true deaths were missed. Shannon and colleagues ${ }^{8}$ compared intensive manual follow up with record linkage and found greater than 95\% ascertainment. There is thus unlikely to be a large bias in the SMRs. Misclassification is unlikely to be related to the cause of death since the cause was not a variable utilised in the matching process. The mortality pattern is thus likely to be unbiased.

We performed multiple testing of a large number of causes of death and time intervals, so some significant findings may have occurred by chance. However, there was prior knowledge that these workers had asbestos exposure and that there was likely to be increasing risk with increasing time from first exposure for those diseases with occupational causation. These factors, as well as consistency with the results of the prior PMR studies, assist with interpretation.

We have no information about the work activities or personal exposures of study subjects. Assuming that exposures were heterogeneous, the risks we observed are thus an average over the workforce. We were obliged to exclude 2466 individuals who had been expelled for non-payment of dues. If their work habits had been different from the subjects included, then their disease risks may also have been different from the workers included in the analysis. We were also dependent on the trade code assigned by the Union. This

Table 4 Lung cancer mortality among members of the Plumbers and Pipefitters United Association by time of start of membership and time from start of membership

\begin{tabular}{|c|c|c|c|c|c|c|c|}
\hline \multirow[b]{3}{*}{ Trade } & \multirow[b]{3}{*}{ Year of beginning membership } & \multicolumn{6}{|c|}{ Years from start of membership } \\
\hline & & \multicolumn{2}{|c|}{$10-19$} & \multicolumn{2}{|c|}{$20-29$} & \multicolumn{2}{|l|}{$\geqslant 30$} \\
\hline & & Obs & $\mathrm{O} / \mathrm{E}$ & Obs & $\mathrm{O} / \mathrm{E}$ & Obs & O/E \\
\hline \multirow[t]{3}{*}{ Pipefitters } & $1950-69$ & 16 & 1.18 & 39 & 1.28 & 56 & 1.53 \\
\hline & 1970-79 & 5 & 0.91 & 3 & 0.58 & - & - \\
\hline & 1980 or later & 2 & 1.3 & - & - & - & - \\
\hline \multirow{3}{*}{ Refrigeration } & $1950-69$ & 4 & 1.35 & 1 & 0.16 & 7 & 1.21 \\
\hline & 1970-79 & 2 & 0.63 & 2 & 0.67 & - & - \\
\hline & 1980 or later & 1 & 1.3 & - & - & - & - \\
\hline \multirow[t]{3}{*}{ Plumbers } & $1950-69$ & 3 & 0.57 & 17 & 0.95 & 53 & 1.31 \\
\hline & 1970-79 & 8 & 1.23 & 10 & 1.43 & - & - \\
\hline & 1980 or later & 3 & 1.17 & - & - & - & - \\
\hline \multirow{3}{*}{ Sprinkler Fitters } & $1950-69$ & 9 & 0.83 & 39 & 1.57 & 45 & 1.32 \\
\hline & 1970-79 & 8 & 1.79 & 6 & 1.32 & - & - \\
\hline & 1980 or later & 1 & 0.9 & - & - & - & - \\
\hline
\end{tabular}


Table 5 Comparison of the results of three North American studies of the United Association of Plumbers and Pipefitters

\begin{tabular}{|c|c|c|c|c|c|c|c|c|}
\hline \multirow[b]{2}{*}{ Tumour site } & \multicolumn{2}{|c|}{ NIOSH 1971 PMR' } & \multicolumn{2}{|c|}{ California (1960-79) PMR ${ }^{2}$} & \multicolumn{2}{|c|}{ Ontario (1950-99) SMR } & \multicolumn{2}{|c|}{$\begin{array}{l}\text { Combined result (random } \\
\text { effects model) }\end{array}$} \\
\hline & PMR & $95 \% \mathrm{Cl}$ & PMR & $95 \% \mathrm{Cl}$ & SMR & $95 \% \mathrm{Cl}$ & $\mathbf{R R}^{*}$ & $95 \% \mathrm{Cl}$ \\
\hline Oesophagus & 1.55 & 0.99 to 2.31 & 1.06 & 0.76 to 1.47 & 1.27 & 0.86 to 1.81 & 1.24 & 1.00 to 1.53 \\
\hline Stomach & 1.05 & 0.7 to 1.5 & 1.29 & 1.06 to 1.58 & 0.67 & 0.41 to 1.02 & 1.01 & 0.71 to 1.45 \\
\hline Colorectal & 1.11 & 0.89 to 1.36 & 0.95 & 0.81 to 1.11 & 1.16 & 0.94 to 1.42 & 1.05 & 0.93 to 1.19 \\
\hline Pancreas & 0.84 & 0.57 to 1.19 & 1.18 & 0.96 to 1.44 & 0.79 & 0.52 to 1.14 & 0.96 & 0.73 to 1.26 \\
\hline Larynx & - & - & 1.17 & 0.79 to 1.73 & 1.32 & 0.72 to 2.21 & 1.22 & 0.88 to 1.68 \\
\hline Lung & 1.22 & 1.08 to 1.37 & 1.41 & 1.31 to 1.52 & 1.27 & 1.13 to 1.42 & 1.31 & 1.19 to 1.44 \\
\hline Kidney & - & - & 1.25 & 0.93 to 1.69 & 0.86 & 0.49 to 1.40 & 1.11 & 0.78 to 1.56 \\
\hline Bladder & 0.92 & 0.55 to 1.44 & 0.9 & 0.66 to 1.22 & 1.11 & 0.68 to 1.68 & 0.95 & 0.76 to 1.19 \\
\hline Prostate & 1.17 & 0.89 to 1.52 & 1.03 & 0.85 to $1 . .24$ & 0.93 & 0.70 to 1.21 & 1.04 & 0.91 to 1.19 \\
\hline Brain & 0.68 & 0.4 to 1.2 & 1.5 & 1.16 to 1.94 & 1.19 & 0.76 to 1.77 & 1.13 & 0.74 to 1.72 \\
\hline Blood/lymph & 1.2 & 0.95 to 1.50 & 1.24 & 1.06 to 1.44 & 1.14 & 0.89 to 1.44 & 1.21 & 1.08 to 1.35 \\
\hline Blood/lymph (plumbers) & 1.46 & 1.03 to 2.01 & 1.25 & 1.01 to 1.55 & 1.16 & 0.78 to 1.67 & 1.28 & 1.09 to 1.51 \\
\hline Blood/lymph (pipefitters) & 1.03 & 0.74 to 1.40 & 1.18 & 0.94 to 1.48 & 1.01 & 0.60 to 1.60 & 1.11 & 0.94 to 1.32 \\
\hline
\end{tabular}

is the code that was applicable at the time the data were provided. There is little movement between trades, but there may have been some misclassification in our analysis resulting in blunting of any differences between the trades.

In many jurisdictions new asbestos installation does not occur. There are, however, substantial amounts of asbestos in place in industrial and commercial environments. The education and training of workers to protect themselves against inhalation hazards will be necessary well into the future.

\section{ACKNOWLEDGEMENTS}

This study was funded by a grant from the Research Advisory Committee of the Ontario Workplace Safety and Insurance Board.

\section{Authors' affiliations}

M M Finkelstein, D K Verma, Program in Occupational Health and Environmental Medicine, McMaster University, Hamilton, Ontario, Canada

\section{APPENDIX}

\section{CALCULATION OF LUNG CANCER RISK ATTRIBUTABLE TO SMOKING}

We use 1987-90 smoking data from Nelson et al. ${ }^{7}$ We assume:

- General public smoking rate is $30 \%$

- Rate among plumbers/pipefitters is $40 \%$
We assume:

- Smoking causes 10-fold increased lung cancer risk

Then:

- Risk $=\%$ non-smokers $\times 1+\%$ smokers $\times 10$

- In the general population $=0.70 \times 1+0.30 \times 10=$ $0.70+3.0=3.7$

- Among plumbers/pipefitters $=0.60 \times 1+0.40 \times 10=$ $0.60+4.0=4.60$

Therefore, relative risk attributable to smoking $=$ $4.60 / 3.70=1.24$

\section{REFERENCES}

1 Kaminski R, Geissert KS, Dacey E. Mortality analysis of plumbers and pipefitters. J Occup Med 1980;22:183-9.

2 Cantor KP, Sontag JM, Heid MF. Patterns of mortality among plumbers and pipefitters. Am J Ind Med 1986;10:73-89.

3 Smith ME, Newcombe HB. Use of the Canadian Mortality Data Base for epidemiological follow-up. Can J Public Health 1982;73:39-46.

4 Coleman M, Douglas A, Hermon C, et al. Cohort study analysis with a Fortran computer program. Int J Epidemiol 1986;15:134-7.

5 Walter SD. Cause-deleted proportional mortality analysis and the healthy worker effect. Stat Med 1986;5:61-71.

6 Egger M, Smith GD, Altman DG. Systematic reviews in health care: metaanalysis in context. London: BMJ Publishing Group, 2001.

7 Nelson DE, Emont SL, Brackbill RM, et al. Cigarette smoking prevalence by occupation in the United States: a comparison between 1978 to 1980 and 1987 to 1990. J Occup Med 1994;36:516-25.

8 Shannon HS, Jamieson E, Walsh C, et al. Comparison of individual follow-up and computerized record linkage using the Canadian Mortality Data Base. Can J Public Health 1989;80:54-7. 